\title{
Mantle Convection and the Thermal Structure of the Plates
}

\author{
Barry Parsons \\ Department of Earth and Planetary Sciences, Massachusetts Institute of Technology \\ Cambridge, Massachusetts 02139 \\ DAN MCKenZIE
}

Department of Geodesy and Geophysics, Madingley Rise, Madingley Road, Cambridge CB3 OEZ, England

\begin{abstract}
Though a simple thermal model of plate creation matches the observed bathymetry and heat flow with considerable accuracy, it only does so because a constant temperature is imposed as a lower boundary condition. A more realistic model is developed here, based on the idea that the thermal structure of the plate becomes unstable and leads to the development of small-scale convection. Convective heat transport then supplies the heat flux needed to match the observations rather than an artificial constant temperature boundary condition. The temperature dependence of the rheology is represented in a simple manner. Below a given temperature the material is assumed to move rigidly, defining an upper mechanical boundary layer. Beneath this rigid layer, where the temperatures are greater, the material is assumed to have a constant Newtonian viscosity. The part of the viscous region where there are significant vertical temperature gradients, immediately below the mechanical boundary layer, forms a thermal boundary layer. As the plate cools, both the mechanical and thermal boundary layers increase in thickness. A local critical Rayleigh number criterion is used to test the stability of the thermal boundary layer. On this basis a convective instability is predicted, its occurrence coinciding with the breakdown of the linear dependence of the depth of the ocean floor on the square root of age. Though the small-scale convection which develops from this instability modifies the thermal structure, the basic observational constraints are shown to be satisfied. The stability criterion is further tested in two different laboratory experiments. These experiments also illustrate a possible form for the instability, with cold dense material breaking away from the base of the plate and being replaced by hotter material from below.
\end{abstract}

\section{INTRODUCTION}

The effects of the cooling of the oceanic plate as it moves away from a midocean ridge have received a good deal of attention, both theoretical and observational. Forsyth [1977] recently reviewed the different measurements that have been made. Variations in mean heat flow, depth, and velocity of surface waves with age all seem to reflect changes in thermal structure. Parsons and Sclater [1977] have shown that variations in mean depth and heat flow can be adequately described by a model of the type originally discussed by McKenzie [1967]. In this model a slab of constant thickness moves away from the ridge crest, its bottom boundary being maintained at constant temperature. A thickness of $125 \mathrm{~km}$ for the slab is given by a simple inversion method based on the analytical properties of the model [Parsons and Sclater, 1977].

The phase and group velocities of Rayleigh waves for periods from 20 to $200 \mathrm{~s}$ are found to increase with increasing age of the ocean floor [Kausel et al., 1974; Weidner, 1974; Leeds, 1975; Forsyth, 1975, 1977]. These data can be inverted to give the seismic velocity structure in different age zones [Leeds et al., 1974; Leeds, 1975; Forsyth, 1975, 1977]. Although the resolution is limited, the overall effect of cooling in increasing the seismic velocities is clear. The top of the low-velocity zone is reasonably well defined. Despite uncertainties about the exact shape of the solidus [Millhollen et al., 1974; Green and Liebermann, 1976], relating the sharp decrease in seismic velocities to the onset of partial melting provides a further constraint on the thermal structure. Forsyth [1977] concluded that the available data were consistent with the model of a cooling plate, $125 \mathrm{~km}$ thick, in a peridotitic mantle.

Such a model requires a supply of heat, the heat flux at the base of the plate increasing further away from the ridge crest. A balance is reached in the older regions between heat sup-

Copyright $(1978$ by the American Geophysical Union. plied to the plate from beneath and heat lost by conduction through it. Small-scale convection in the upper mantle has been suggested as a means of maintaining the necessary vertical heat transport [Richter, 1973; Richter and Parsons, 1975; McKenzie and Weiss, 1975]. In part this suggestion stemmed from the difficulty encountered in numerical experiments in preventing convection in boxes whose horizontal extent was several times that of the vertical dimension from breaking up into many smaller cells. In a model of the thermal evolution of the plates which includes the possibility of small-scale convection, it is necessary to distinguish between two types of boundary layers. The mechanical boundary layer moves as a rigid spherical cap and carries the magnetic anomalies. Beneath the mechanical boundary layer is a thermal boundary layer which is also cooled by heat lost upward but within which motions not simply related to the motion of the surface can occur. Neither boundary layer has sharp boundaries, and hence this model is more physically realistic than that used by McKenzie [1967].

An observation that initially seemed to support the notion of small-scale convection as the principal means of vertical heat transport in the upper mantle was the apparent approach of the heat flow measurements to a constant background value in old ocean basins. Although on closer examination the heat flow cannot in fact discriminate between an approach to a constant level and continued cooling, an equivalent argument can still be made on the basis of the variation of depth with age [Parsons and Sclater, 1977]. The mean depth of the ocean floor behaves in a very simple way as a function of age (Figure 1). Out to an age of about $70 \mathrm{~m} . \mathrm{y}$. the depth increases linearly as $t^{1 / 2}$, where $t$ is the age of the ocean floor. For larger ages than this the linear relationship breaks down, and the depth increases less rapidly, following a simple exponential decay to a constant value. For ages younger than $70 \mathrm{~m}$.y. the form of the variation can be accounted for by a variety of thermal models. 


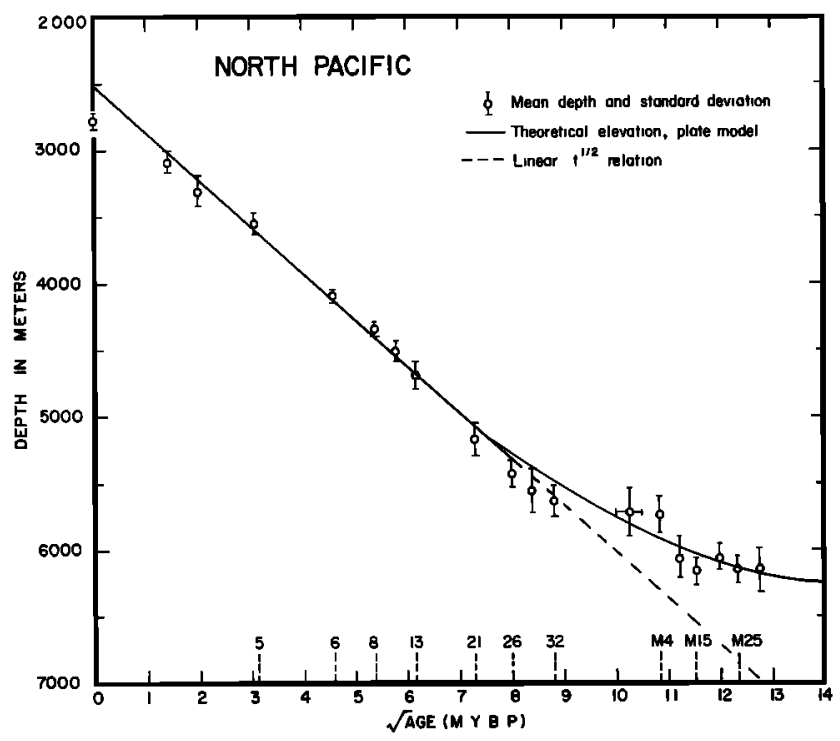

Fig. 1. Plot of mean depth in the North Pacific versus the square root of age. Numbers at the bottom of the figure denote selected Cenozoic and Mesozoic magnetic anomalies [from Parsons and Sclater. 1977].

One is the cooling plate model described above. Another simply allows the material to lose heat at the upper boundary without restricting the depth to which cooling can occur [Davis and Lister, 1974]. A third model allows the bottom boundary to migrate and assumes that it is at the melting point of the material [Parker and Oldenburg. 1973]. For sufficiently small ages the behavior in all these models is principally determined by cooling from similar initial temperature profiles that are uniform with depth right up to or almost up to the upper boundary. However, for greater ages the cooling has penetrated deep enough for the influence of some bottom boundary condition to be felt. Heat is supplied so that the depth to any given isotherm increases less rapidly, and accordingly, the depth of the ocean floor increases less rapidly. The alternatives to the plate model can be modified to allow for an input of heat from below [Crough, 1975; Oldenburg. 1975], but then to a greater or lesser degree they approximate that model.

Alternative mechanisms, other than small-scale convection, have been suggested in order to supply the required heating and reproduce the observed variation of depth and heat flow with age [Forsyth, 1977; Schubert et al., 1976]. Any thermal model of a plate that satisfies the observed variation of surface heat flow and depth with age is constrained to have the same total heat sources provided by a combination of internal heat generation and heating from below. This can be seen by considering the energy balance of a column through the plate, height $a$, and width $d x$, observed in a stationary reference frame (Figure 2). We assume that lateral temperature variations in the plate are confined above the base of the column. Horizontal heat conduction is neglected, this being a good assumption away from the ridge axis. The energy balance is then

$$
\begin{aligned}
\rho_{0} C_{p} u \int_{0}^{a}[T(x+d x, z)-T(x, z)] d z & +\left(q_{u}-q_{b}\right) d x \\
& =d x \int_{0}^{a} H(z) d z
\end{aligned}
$$

where the velocity $u$ is taken to be constant. Other terms are defined in Figure 2. The change in depth across the column is given by

$$
\begin{aligned}
d(x+d x)-d(x)=- & \frac{\alpha \rho_{0}}{\left(\rho_{0}-\rho_{w}\right)} \\
& \quad \int_{0}^{a}[T(x+d x, z)-T(x, z)] d z
\end{aligned}
$$

where $\alpha$ is the volumetric expansion coefficient, $\rho_{0}$ the reference mantle density, and $\rho_{w}$ the density of seawater and both (1) and (2) are correct to first order in $(\alpha T)$. The difference in internal energy between material leaving and entering the column is therefore proportional to the change in depth. Combining (1) and (2) results in the relation

$$
\frac{-\left(\rho_{0}-\rho_{w}\right) C_{p}}{\alpha} \frac{\partial d}{\partial t}+q_{u}=q_{b}+\int_{0}^{a} H(z) d z
$$

where $t=x / u$, the age of the ocean floor. As $d(t)$ and $q_{u}(t)$ are presumed known, then the right-hand side of $(3)$ is also known as a function of $t$. If $q_{b}$ and $H(z)$ can be neglected, then equating the left-hand side of (3) to zero provides a relation between variations of depth and surface heat flux. Lister [1977] derived such a relationship from the $t^{1 / 2}$ and $t^{-1 / 2}$ dependences of the two observables which hold for small enough $t$. Thermal models of a plate that predict the observed functions $d(t)$ and $q_{u}(t)$ have identical total heat sources given by the right-hand side of (3). They differ only in the way that the heat sources are partitioned between $q_{b}$ and $H(z)$ and, more important, in the heat transport mechanism used to supply $q_{b}$. Forsyth [1978] suggested that the required heating could be provided by radioactive sources distributed in the upper $300 \mathrm{~km}$ of the mantle, the vertical heat transport mechanism being conductive. Schubert et al. [1976] used shear stress heating produced in the large-scale flow associated with the plate motion. The vertical heat transport mechanism was still predominantly conductive. Each of the above mechanisms produces similar thermal structures and hence can account reasonably well for the observations. The problem of the stability of a large-scale flow with such a thermal structure in the upper boundary layer has not been considered. This provides a means of discriminating between the different models, since some form of smallscale convection will clearly develop in those cases that can be shown to be unstable.

The scheme that we attempt to justify in this paper is illustrated in Figure 3. Material moves away from the ridge crest, losing heat conductively with the upper boundary fixed at $0^{\circ} \mathrm{C}$. There is no small-scale convection at this point, because the overturning of the large-scale circulation precludes the existence of the cold upper conductive boundary layers of such convection cells. Initially, the only heat brought from below is that transported in the large-scale flow, and cooling occurs exactly as for a half space. The mechanical properties of the material will vary rapidly with temperature. We represent this temperature dependence by assuming that below a certain temperature the material behaves rigidly. Above that temperature the material is treated as having a uniform Newtonian viscosity. This is undoubtedly an oversimplification of complex rheological behavior, but such a two-layer model has proved useful in discussing stress balances in the large-scale flow [Richter, 1977; Richter and McKenzie, 1978]. Also the calculations of Schubert et al. [1976] suggest that such a representation of the rheology should be adequate for the purposes of this paper. 


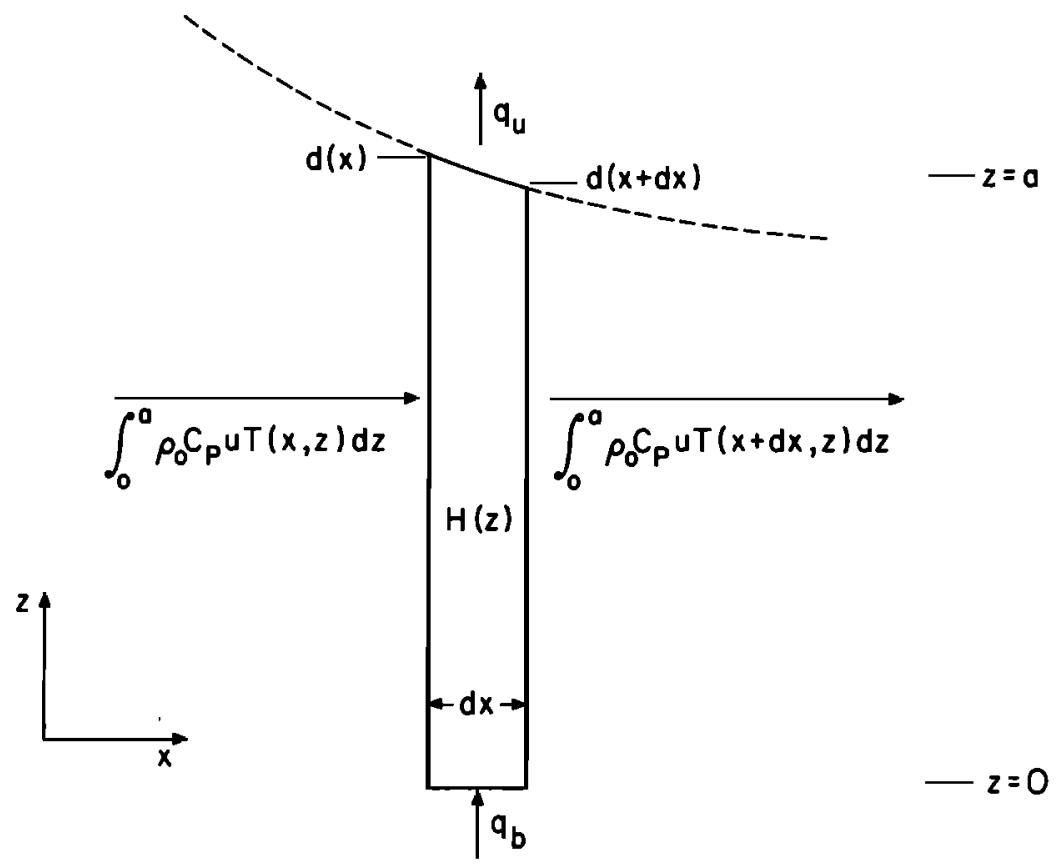

Fig. 2. Sketch to illustrate the energy balance for a column of material in the plate. The relation of the energy balance to the change in depth $d(x)$ across the column, and to the upper and bottom heat fluxes, $q_{u}$ and $q_{b}$, is discussed in the text. Other variables are as follows: $T(x, z)$ is the temperature, $\rho_{0}$ the density, $C_{p}$ the specific heat, $u$ the plate velocity, and $H(z)$ the radioactive heat content of the column.

As cooling proceeds, the spacing of the isotherms increases. The mechanical boundary layer lies between the surface and the isotherm chosen to represent the transition between rigid and viscous behavior. This isotherm and another chosen isotherm are used to provide a measure of the temperature gradient within the viscous region immediately below the mechanical boundary layer. We call the region between these two isotherms the thermal boundary layer. The thicknesses of the two boundary layers will increase with age as shown in Figure 3. If at an age of $70 \mathrm{~m} . \mathrm{y}$. the thickness of the thermal boundary layer has increased sufficiently that it becomes unstable on the basis of a local Rayleigh number criterion for the boundary layer, then cold material will break away from the bottom of the lithosphere, and mantle material at the assumed basal temperature will replace it. As cooling proceeds further, the small-scale convection increases in amplitude until a balance is reached between the heat conducted through the plate and heat transported vertically by the small-scale convection. This, in turn, depends on the heat sources distributed within the convecting region and supplied below it from the lower mantle. The upper thermal boundary layer of the small-scale convection occupies the region immediately below the mechanical boundary layer, hence the name for this region given above.

The small-scale convection maintains a mean temperature structure in the upper mantle that is essentially adiabatic, apart from its upper boundary layer. As the plates move apart, material can ascend adiabatically with little distortion of the isotherms in the upper mantle. This is distinctly different from a convective model in which the plates form the upper boundary layer of a single convection cell [Turcotte and Oxburgh, 1967]. In that case there is a large temperature contrast between the ascending material and the adiabatic core of the cell, which provides a major component in driving the cell.

Once the instability occurs, the overturning produced by the onset of small-scale convection effectively keeps the mean temperature constant at the depth to which cooling had penetrated at that time. This depth then effectively defines the plate

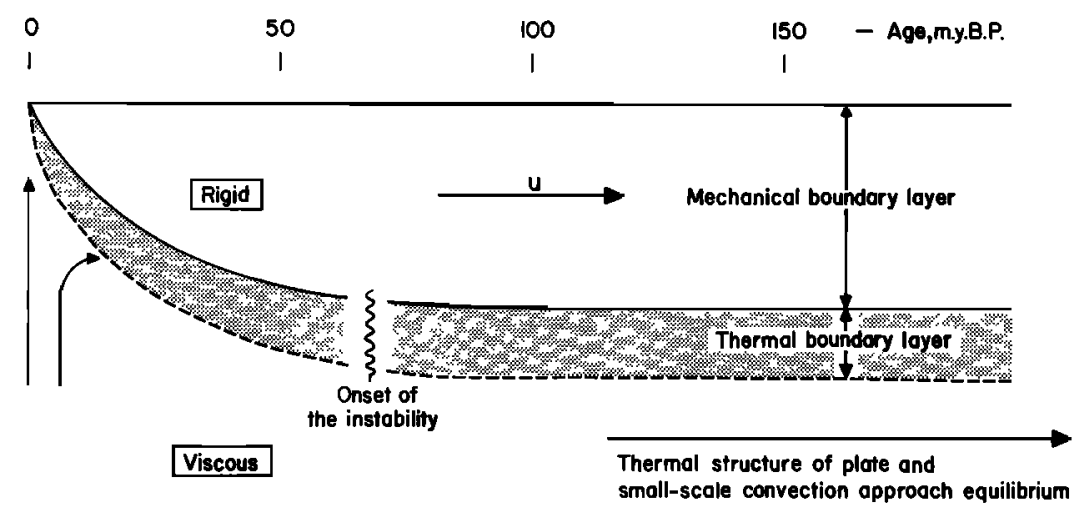

Fig. 3. Schematic diagram showing the division of the plate into rigid and viscous regions and the occurrence of an instability in the bottom viscous part of the plate. 
thickness determined from fits to the variations of depth and heat flow versus age and is the sum of the thicknesses of the mechanical and thermal boundary layers. Both are included because significant mean temperature differences relative to the temperature profile under the ridge crest occur above this depth, and the variation of depth versus age is determined principally by such temperature differences.

The basic argument that we use below depends on the existence of a local critical Rayleigh number criterion to predict instability in the thermal boundary layer. Although such a criterion is intuitively reasonable, it cannot be rigorously justified. Therefore after the use of this criterion in section 2 in connection with the hypothesis described above, its application in a variety of other physical situations is also considered. In all cases, agreement is obtained with either numerical or experimental results. This provides confidence that the predictions based on a local critical Rayleigh number criterion will be at least qualitatively correct.

\section{The Initiation of Small-Scale Convection}

Figure 3 illustrates the scheme that is to be tested. Material is assumed to rise adiabatically at the ridge crest. Estimates of the temperature beneath spreading centers have been made in a number of different ways and give reasonable agreement. In order to form olivine tholeiites by partial melting of a model pyrolite mantle, temperatures between $1300^{\circ}$ and $1400^{\circ} \mathrm{C}$ for the depth range 30-60 km are required [Wyllie, 1971; Green. 1972]. Application of plagioclase geothermometry to ocean ridge basalts gives temperatures ranging from $1200^{\circ}$ to $1400^{\circ} \mathrm{C}$ [Scheidegger, 1973; Frey et al., 1974]. Temperatures around $1350^{\circ} \mathrm{C}$ were obtained independently of the other parameters of the plate model by fits to the empirical depth-age curve [Parsons and Sclater, 1977]. For the calculations below, a uniform temperature

$$
T_{1}=1300^{\circ} \mathrm{C}
$$

is assumed, the small adiabatic gradient being neglected.

The decision to subdivide the cooling plate into two regions, one quasi-rigid and the other uniformly viscous, is based on the very rapid variation of viscosity with temperature. A number of different mechanisms for creep in solids exist [Stocker and $A$ shby, 1973]. Dislocation creep and diffusion creep, in particular the former, are appropriate to the range of stresses and temperatures in the upper mantle. These mechanisms have an exponential dependence on temperature arising from the form of the diffusion coefficient, both processes depending on the diffusion of oxygen ions within the lattice. As an example, the viscosity for Nabarro-Herring creep is given by

$$
\nu=\frac{k_{b} T R^{2}}{10 m_{0} D_{0}} \exp \left(\frac{E+p V}{k_{b} T}\right)
$$

where $\nu$ is the kinematic viscosity, $k_{b}$ Boltzmann's constant, $R$ the mean grain radius, $D_{0}$ the reference constant in the diffusion coefficient, $m_{0}$ the mass of an oxygen ion, $E$ an activation energy, $V$ an activation volume, $T$ the absolute temperature, and $p$ the pressure. The following tabulation gives the values of physical parameters that have been used in this paper:

$$
\begin{aligned}
\rho_{0} & =3.33 \mathrm{Mg} \mathrm{m}^{-3} ; \\
g & =10 \mathrm{~m} \mathrm{~s}^{-1} ; \\
R & =0.5 \mathrm{~mm} ; \\
D_{0} & =5 \times 10^{-4} \mathrm{~m}^{2} \mathrm{~s}^{-1} ; \\
E & =4.25 \mathrm{eV} ; \\
\nu_{0} & =2 \times 10^{17} \mathrm{~m}^{2} \mathrm{~s}^{-1} ;
\end{aligned}
$$

$$
\begin{aligned}
\kappa & =8 \times 10^{-7} \mathrm{~m}^{2} \mathrm{~s}^{-1} ; \\
C_{p} & =1.17 \times 10^{3} \mathrm{~J} \mathrm{~kg}^{-1}{ }^{\circ} \mathrm{C}^{-1} ; \\
\alpha & =3 \times 10^{-5}{ }^{\circ} \mathrm{C}^{-1} ; \\
R a_{c} & =10^{3}
\end{aligned}
$$

The value of $4.25 \mathrm{eV}$ for the activation energy is at the lower end of the range of experimentally determined values. Post [1977] obtained $4.06 \mathrm{eV}$ for the high-temperature creep of Mt. Burnett dunite in a hydrous environment. Higher values around $5.4 \mathrm{eV}$ are found for dry olivine [Kohlstedt and Goetze. 1974]. There is a good deal of uncertainty associated with the preexponential coefficient in (5), in particular for the grain size. In the upper $100 \mathrm{~km}$ the pressure effect is small, and the temperature variation alone is plotted in Figure 4. Decreasing the temperature from $1300^{\circ}$ to $900^{\circ} \mathrm{C}$ increases the viscosity by slightly more than 4 orders of magnitude. We have picked the isotherm

$$
T=0.75 T_{1}
$$

or $T^{\prime}=975^{\circ} \mathrm{C}$ in this case, to represent the transition from quasi-rigid to viscous behavior. As material moves away from the ridge crest and cooling proceeds, the temperature profile is initially given by

$$
T=T_{1} \operatorname{erf}\left\{z /\left[2(\kappa t)^{1 / 2}\right]\right\}
$$

where $z$ is the depth, $t$ the time, and $\kappa$ the thermal diffusivity. From (6) and (7) the thickness of the mechanical boundary layer therefore grows as

$$
\Delta=1.63(\kappa t)^{1 / 2}
$$

In order to provide a measure of the temperature gradient in the viscous region we follow another isotherm chosen to be

$$
T^{\prime \prime}=0.97 T_{1}
$$

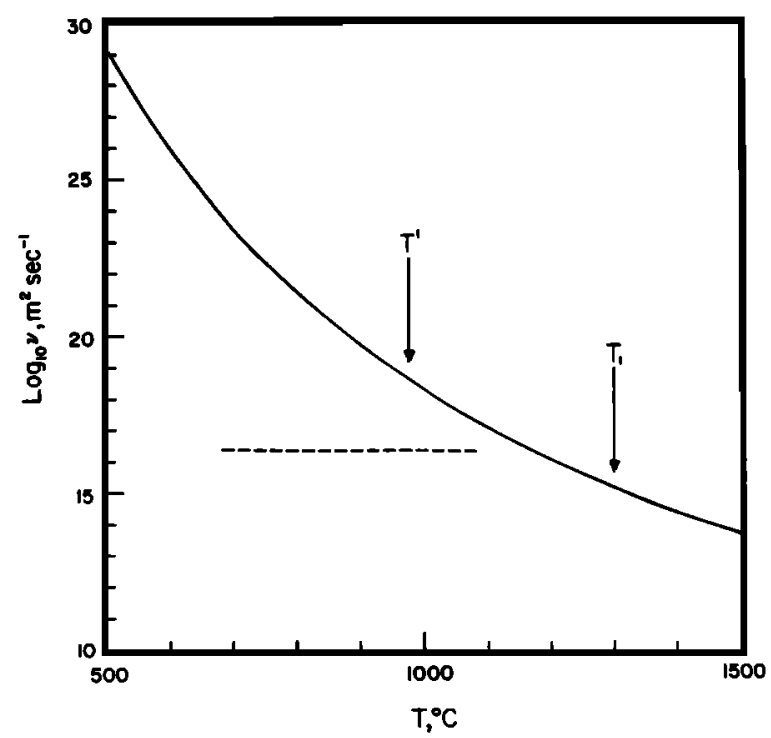

Fig. 4. Plot of viscosity versus temperature for the creep law given by (5) and physical parameters listed in the tabulation in the text. Any other creep law will display the same strong temperature dependence. The arrow labeled $T$ denotes the temperature chosen to represent the division between rigid and viscous behavior. $T_{1}$ is the mantle temperature below the plate. The dashed line shows the value of viscosity required for the instability to occur after $70 \mathrm{~m} . \mathrm{y}$. 


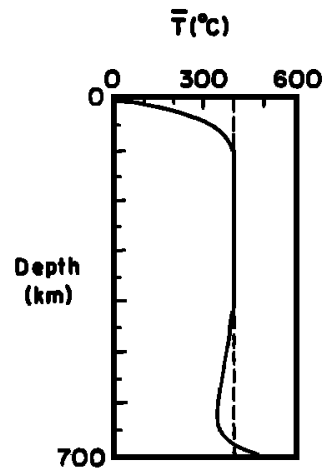

$\mathbf{T}$

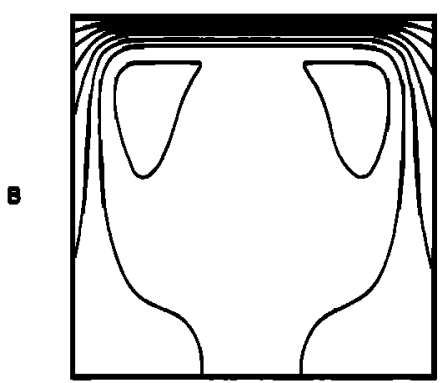

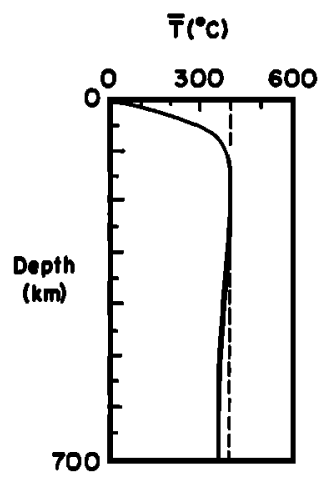

Fig. 5. Isotherms and horizontally averaged temperature structure for steady state convection in square boxes for (a) $30 \mathrm{~mW} \mathrm{~m}^{-2}$ from below and $40.7 \mathrm{nW} \mathrm{m} \mathrm{m}^{-3}$ from within and $(b) 83.6 \mathrm{nW} \mathrm{m}^{-3}$ from within. Both have the same mean heat flux at the surface and are calculated for a $24 \times 24$ mesh. Isotherms are contoured at intervals of $60^{\circ} \mathrm{C}$ [after McKenzie et al., 1974].

The isotherms $T^{\prime}$ and $T^{\prime \prime}$ define a thermal boundary layer across which there is a temperature drop

$$
\Delta T=T^{\prime \prime}-T
$$

The thickness of the thermal boundary layer grows as

$$
\delta=1.43(\kappa t)^{1 / 2}
$$

The thermal boundary layer is assumed to become unstable when a locally defined Rayleigh number exceeds a critical value. In other words, the local stability criterion is given by

$$
g \alpha \Delta T \delta^{\circ} / \kappa \nu=R a_{c}
$$

where $g$ is the gravitational acceleration, $\alpha$ the volumetric thermal expansion coefficient, $\nu$ the kinematic viscosity, and
$R a_{c}$ the critical Rayleigh number. The values that we have used are given in the preceding tabulation. Substituting suitable values for the physical parameters in (12) would give the age, $l_{c}$, at which an instability would occur. Because of uncertainties in the values for the viscosity, rather than do this, we assert that $t_{c}=70 \mathrm{~m} . \mathrm{y}$. as suggested by the variation of depth with age and ask what value of $\nu$ is needed for (12) to hold. Using the values in the tabulation, a value for the viscosity of

$$
\nu=2.33 \times 10^{16} \mathrm{~m}^{2} \mathrm{~s}^{-1}
$$

is obtained. This is not unreasonable, considering the values plotted in Figure 4 and that (13) represents an average viscosity across the boundary layer. Values for the mean mantle viscosity of $2 \times 10^{17} \mathrm{~m}^{2} \mathrm{~s}^{-1}$ are obtained from studies of postglacial uplift [Cathles, 1971; Peltier and Andrews, 1976]. Richter and McKenzie [1978] calculated values ranging from $2 \times 10^{10} \mathrm{~m}^{2} \mathrm{~s}^{-1}$ to $2 \times 10^{17} \mathrm{~m}^{2} \mathrm{~s}^{-1}$ by considering the balance between viscous stresses and the buoyancy forces driving the motion of subducted plates. In their models they also required a low-viscosity layer to decouple the plate motion from the mantle beneath; values in this layer as low as $10^{14} \mathrm{~m}^{2} \mathrm{~s}^{-1}$ were suggested. Hence we see that the value given here falls within the range of probable values obtained by various different methods.

\section{The Effect of Small-Scale Convection ON THE Thermal STruCture}

The model used above to determine where the thermal boundary layer becomes unstable uses the thermal structure given when conduction is the only means of vertical heat transport. The development of the boundary layer instability leads to convective heat transport, and therefore the mean temperature structure can only be obtained by solving nonlinear equations. We shall not attempt this here. Instead we can use the same boundary layer stability criterion to construct a simple model representing steady state convection. The analytical relationships obtained in this way can be used to test whether the depth and heat flux for infinitely old sea floor, here called the equilibrium state, agree with the extrapolations obtained by fitting a plate model to the observations.

The starting point is a scheme suggested by Howard [1966] as being equivalent to turbulent $R$ ayleigh-Benard convection in some average sense. This is adapted here to the case of convection driven by internal heat sources or a combination of internal heat sources and fixed heat flux from below. This mode of heating is more appropriate to the upper mantle than the uniform temperature difference used in Rayleigh-Benard convection [McKenzie et al., 1974]. The steady state in such
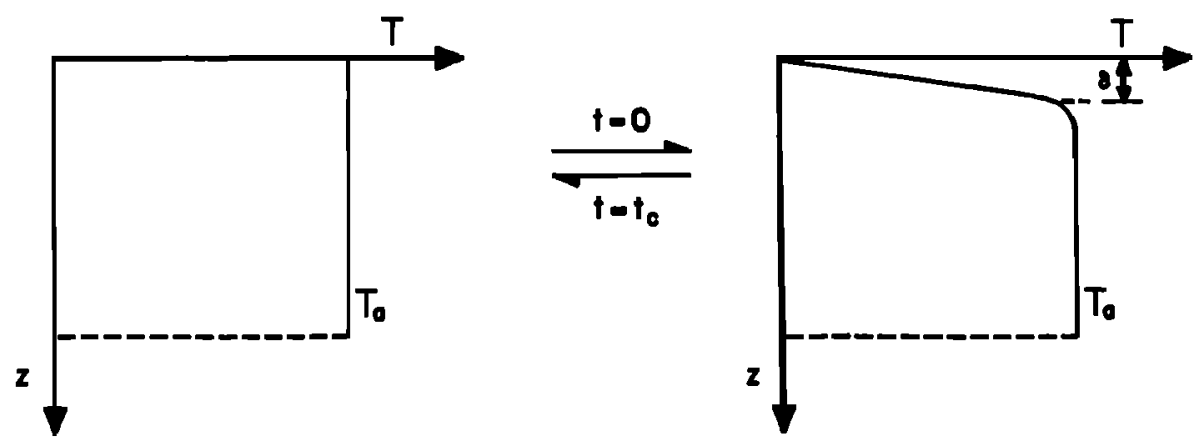

Fig. 6. Illustration of a simplified model for convection at high Rayleigh numbers driven by internal heating. 
convection produces a mean temperature profile which is essentially isothermal from the bottom of the layer up to a thin boundary layer across which the temperature drops rapidly to match the zero temperature boundary condition on the upper surface (Figure 5). A boundary layer at the bottom of the convecting layer only develops significantly as the proportion of the total heating provided by heat flux from below increases.

Following Howard [1966], we assume that this can be modeled in a time-averaged sense by starting with a completely isothermal layer, temperature $T=T_{a}$, and at time $t=0$, imposing an upper boundary condition $T=0$ (Figure 6). As before, an upper thermal boundary layer develops by conductive cooling, the temperature being given by

$$
T=T_{a} \operatorname{erf}\left\{z /\left[2(k t)^{1 / 2}\right]\right\}
$$

This boundary layer becomes unstable at a time $t=t_{c}$, when a local Rayleigh number defined for the boundary layer reaches some critical value. The local stability criterion is given by

$$
g \alpha T_{\alpha} \delta^{3} / \kappa \nu=R a_{c}
$$

where the boundary layer thickness at this time is taken to be

$$
\delta=2\left(\kappa t_{c}\right)^{1 / 2}
$$

that is the thermal diffusion length scale at $t=t_{c}$. When the boundary layer becomes unstable, the fluid in the boundary layer is replaced in a time short in comparison to $t_{c}$ [Howard, 1966] by fluid at the temperature $T_{a}$. Hence the initial state is restored, and the process repeats itself (Figure 6). The average heat flux over the interval $\left(0, t_{c}\right)$ is

$$
F=\frac{2 k T_{a}}{\left(\pi \kappa t_{c}\right)^{1 / 2}}=\frac{4 k T_{a}}{\pi^{1 / 2} \delta}
$$

with $k\left(=\rho C_{p} k\right)$ the thermal conductivity, $\rho$ being the density and $C_{p}$ the specific heat. In the case of convection driven by internal heating, it is $F$ rather than $T_{a}$ which is specified, and $T_{a}$ adjusts until a balance is obtained with the internal heat sources. From (15) and (17) a relation between $F$ and $T_{a}$ can be obtained:

$\log _{10} T_{a}=0.75 \log _{10} F+0.25 \log _{10}\left(\frac{\pi^{3 / 2} \nu R a_{c}}{64 \rho^{8} C_{p}{ }^{3} \kappa^{2} g \alpha}\right)$

McKenzie et al. [1974] obtained a similar relation based on their numerical calculations:

$$
\log _{10} T_{a}=0.76 \log _{10} F+3.58
$$

when $T_{a}$ is given in degrees Celsius and $F$ is measured in watts per square meter. This relationship was actually derived for the maximum temperature in the cell, but as can be seen from the isotherms and mean temperature structure shown in Figure $5 b$, the relationship should hold for the temperature jump across the boundary layer in the mean temperature structure. The simple time-averaged model based on a local critical Rayleigh number criterion gives the correct form of the relation. The value of $R a_{c}$ that is to be applied to the stability of the boundary layer can be obtained by equating the constants in (18) and (19). Using the values of the physical parameters given by McKenzie et al. [1974], we find that

$$
R a_{c}=473
$$

The critical Rayleigh number for free-free boundaries is $R a_{c}=$ 658, with constant temperature specified on the bottom boundary, or $R a_{c}=385$, with constant flux on the bottom boundary.
Averaging the temperature profile (equation (14)) over the interval $\left(0, t_{c}\right)$ gives the mean temperature structure of the boundary layer:

$T=T_{a}\left[\operatorname{erf}(\xi)+\left(2 \xi / \pi^{1 / 2}\right) \cdot \exp \left(-\xi^{2}\right)-2 \xi^{2} \operatorname{erfc}(\xi)\right]$

where $\xi=z / 2\left(\kappa t_{c}\right)^{1 / 2}$. Despite the fact that the above model is very crude, the reasonable value obtained for $R a_{c}$ and the correct form of the relationship (equation (18)) suggest that reasoning based on the local stability of the boundary layer gives sensible results.

In the equilibrium state the mean thermal gradient in the mechanical boundary layer is linear, and its thickness $\Delta^{\prime}$ (Figure 7) depends on the heat flux $F$ through its base:

$$
\Delta^{\prime}=\left[k\left(T_{1}-T_{a}\right)\right] / F
$$

Parsons and Sclater [1977] estimated the heat flux through the base of the plate in the equilibrium state to be $34 \mathrm{~mW} \mathrm{~m}^{-2}$, so that $\Delta^{\prime}=91 \mathrm{~km}$. The length scale $\delta$ of the thermal boundary layer can be calculated from (15). Values of $\nu=2.33 \times 10^{18} \mathrm{~m}^{2}$ $\mathrm{s}^{-1}, T_{a}=325^{\circ} \mathrm{C}, R a_{c}=10^{3}$, and otherwise as in the tabulation, were used. We find that $\delta=58 \mathrm{~km}$ and, substituting this value in (17), we find a value of $F=40 \mathrm{~mW} \mathrm{~m}^{-2}$ for the equilibrium heat flux. Considering the uncertainty in the equilibrium value of the heat flux and the crudeness of the model, this is quite reasonable agreement.

In the equilibrium state, (21) gives the temperature structure in the thermal boundary layer. If depths are measured downward from the top of the mechanical boundary layer, the temperature in both the boundary layers in the equilibrium state is given by

$$
\begin{gathered}
T(z)=\left[\left(T_{1}-T_{a}\right) z\right] / \Delta^{\prime} \quad 0<z<\Delta^{\prime} \\
T(z)=T_{1}+T_{a}\left[\left(2 / \pi^{1 / 2}\right) \xi \exp \left(-\xi^{2}\right)\right. \\
\left.-\left(1+2 \xi^{2}\right) \operatorname{erfc}(\xi)\right] \quad z>\Delta^{\prime}
\end{gathered}
$$

where $\xi=\left(z-\Delta^{\prime}\right) / \delta$ in this case. The elevation of the ridge crest relative to infinitely old sea floor is given by

$$
e_{R C}=\frac{\rho_{0} \alpha}{\left(\rho_{0}-\rho_{w}\right)} \int_{0}^{\infty}\left[T_{1}-T(z)\right] d z
$$

if variations in depth of the ocean floor are isostatically compensated. Parsons and Sclater [1977] estimated a ridge crest elevation of $3900 \mathrm{~m}$ relative to an asymptotic depth of $6400 \mathrm{~m}$. Substitution of (23) in (24) results in a value of $e_{R C}=3470 \mathrm{~m}$, in good agreement with the observations, since most of the difference from the observed value is due to the values of $\alpha$ and $T_{1}$ adopted here for simplicity, which differ from those estimated by Parsons and Sclater [1977]. As well as satisfying the equilibrium constraints reasonably well, the convective model automatically gives a linear relationship between depth and $t^{\mathbf{1 / 2}}$ out to 70 m.y. and the breakdown of the relationship at this age. We have not attempted to solve the nonlinear equations describing the development of the instability and so cannot test the behavior of the convective model between 70 m.y. and the equilibrium state.

For a plate model the properties of the model are principally determined by the plate thickness. In the case of the convective model, however, the thermal boundary layer has a thickness and temperature drop across it which depend not only on the heat flux but also on the viscosity value. This dependence can be seen in (18). As an illustration, we can ask what viscosity value is needed, given $T_{a}=325^{\circ} \mathrm{C}$ to satisfy the observed heat flux of $34 \mathrm{~mW} \mathrm{~m}^{-2}$. Using (15) and (17), a viscosity value

$$
\nu=3.9 \times 10^{10} \mathrm{~m}^{2} \mathrm{~s}^{-1}
$$




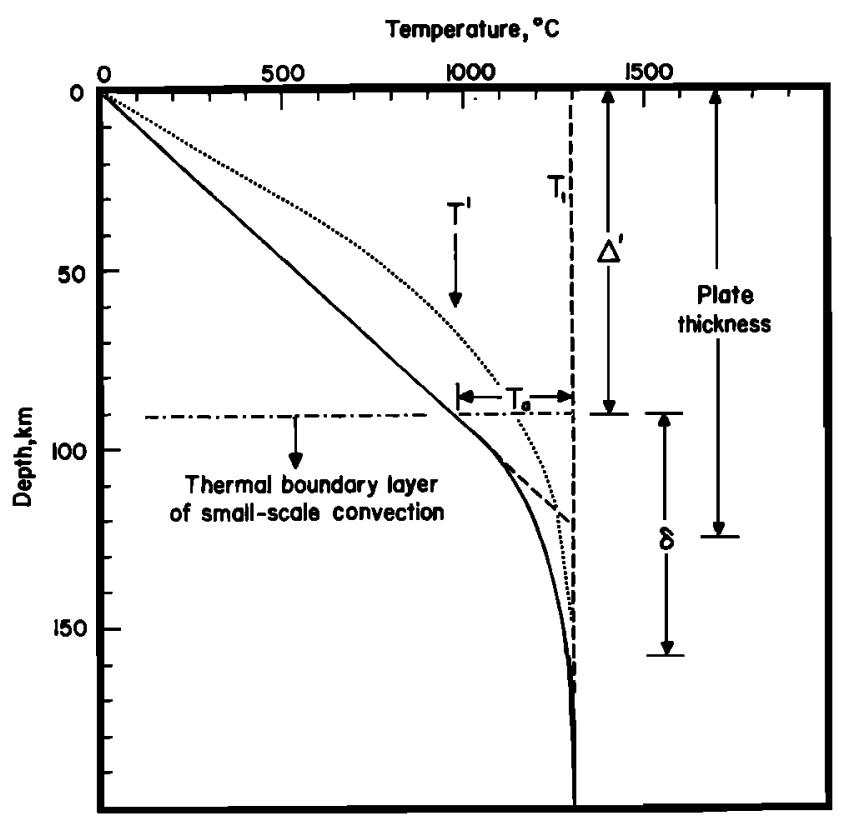

Fig. 7. The solid curve is the equilibrium thermal structure of the plate and shows the part played by the thermal boundary layer of small-scale convection. The mean convective thermal structure differs from a linear profile expected for the plate model at the base of the thermal boundary layer. The dotted curve is the temperature structure given by (7) for an age of 70 m.y. immediately before the onset of convection. Parameter $\Delta^{\prime}$ is the thickness of the mechanical boundary layer in equilibrium, and $\delta$ is the thermal length scale governing the time-averaged temperature structure in the boundary layer. Also shown is the plate thickness obtained by fits to depth and heat flow data.

is obtained, slightly greater than the value in (13). Figure 7 shows the mean temperature for the convective model in this case. The temperature structure differs significantly from the linear gradient expected for the plate model only at the base of the thermal boundary layer. It is encouraging that both the onset of small-scale convection and the asymptotic behavior can be matched with viscosity values lying within the range of other estimates.

It should be noted that the definition of the thickness of the thermal boundary layer used in this section differs slightly from that used in the previous section. In the equilibrium state the temperature profile in the mechanical boundary layer is essentially fixed, and only the turning over to fluid beneath it is considered. Before the instability occurs, the temperature is also varying in the mechanical boundary layer, and hence the gradients in the thermal boundary layer will be different. It is clear, however, that in all cases the boundary layer thickness is proportional to $\left(\kappa t_{c}\right)^{1 / 2}$.

\section{BOUNDARY LAYER INSTABILITIES IN LABORATORY EXPERIMENTS}

\section{a. Transient Cooling From Above}

The experiments described here were performed by using a convection tank based on the design of Chen and Whitehead [1968], which is fully described elsewhere [Richter and Parsons, 1975; Whitehead and Parsons, 1978]. A layer of fluid is bounded above and below by horizontal glass surfaces which are maintained as isothermal boundaries to a good approximation. These are separated by machined spacers which control the depth of the layer. Convection is observed by passing a slightly divergent beam of light through the layer of fluid. Horizontal temperature differences associated with the con- vection produce changes in the refractive index. For instance, cold downwelling fluid has a higher refractive index than surrounding fluid and causes convergence of the light beam. A translucent screen interrupts the beam after it passes through the fluid. The photograph shown in Figure 8 represents a view from above the convecting layer, bright regions marking cold downwelling fluid and dark regions hot upwelling fluid. The working fluid was a Dow Corning 200 silicone oil with a Prandtl number $(=\nu / \kappa)$ of 8600 , the large Prandtl number limit being appropriate for mantle convection. Values of the physical parameters for the oil are $\rho_{0}=0.971 \mathrm{Mg} \mathrm{m}^{-8}, \nu=$ $10^{-3} \mathrm{~m}^{2} \mathrm{~s}^{-1}, \alpha=9.6 \times 10^{-4}{ }^{\circ} \mathrm{C}^{-1}$, and $\kappa=1.16 \times 10^{-7}$ $\mathrm{m}^{2} \mathrm{~s}^{-1}$. The viscosity is, to a good approximation, independent of temperature.

Convection produced by cooling from above has been considered in connection with the cooling of the surfaces of oceans and lakes. Spangenberg and Rowland [1961] and Foster [1965b] observed convection induced in water by evaporative cooling at its upper surface. In the former case a Rayleigh number of 1183 was calculated from the temperature structure in the upper boundary layer at the onset of convection. The experiments here were performed to test further the applicability of a local critical Rayleigh number criterion for the upper boundary layer and to provide an illustration of the form of convection that might be expected.

Two experiments were performed for layer depths $d$ of 5 and $12 \mathrm{~cm}$. Both boundaries were maintained at the same temperature $\left(40^{\circ} \mathrm{C}\right)$ for a time greater than the thermal time constant $d^{2} / \kappa$ of the layer. This produces an initially isothermal layer of fluid. At $t=0$ the heating of the bottom boundary was stopped, and the temperature of the upper boundary was rapidly reduced. The bottom boundary temperature varies very slowly subsequently in comparison to that of the upper boundary, so that essentially, the fluid was being cooled from above with zero heat flux from below. The instability occurs in the cold upper boundary layer, cold fluid breaking away and forming concentrated downwellings. The boundary layer thickness at this point, $t=t_{c}$, is estimated from $\delta=2\left(\kappa t_{c}\right)^{1 / 2}$, the thermal diffusion length scale. The value of the boundary layer thickness, $\delta \sim 1.9 \mathrm{~cm}$, was always much smaller than the depth of the fluid layer. A value for the temperature drop across the boundary layer was obtained from the mean difference between the upper boundary temperature and the initial temperature of the fluid over the interval $\left(0, t_{\mathrm{c}}\right)$. From (12), values of $R a_{c} \sim 2.1 \times 10^{9}$ were obtained. This provides an upper limit to the critical Rayleigh number for the boundary layer, since the instability must develop to a certain extent before it can be observed with this visualization method. The local stability criterion applied to the upper boundary layer therefore provides a reasonable guide to the onset of convection in the fluid.

The form of the convection always consisted of localized downwellings. The upwelling occurs over a diffuse area, since no localized dark upwelling regions are observed. An example of the developed form of the convection is given in Figure 8. The horizontal length scale of the convective pattern was observed to decrease as the convection developed after the initial instability. Downwellings are seen to develop with time in different parts of the tank. If attention is concentrated on a small area, the mean effect of new downwellings developing and moving across this area can be seen to be equivalent to the time-averaging process considered above. These results are consistent with the observations of Whitehead and Chen [1970], Spangenberg and Rowland [1961], and Foster [1965b]. Convection dominated by localized downwellings and diffuse 


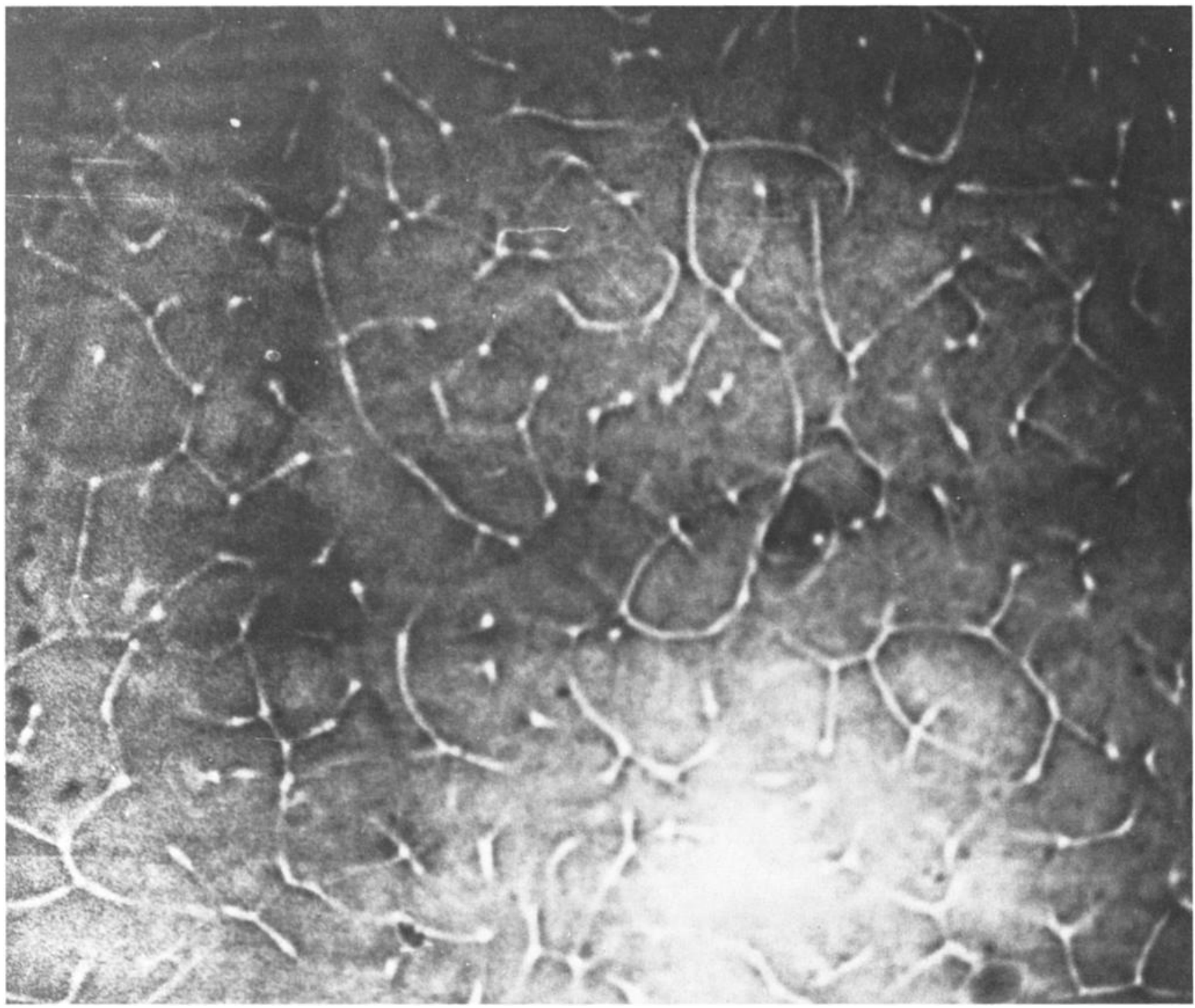

Fig. 8. Example of the form of convection produced by cooling from above. Note the predominance of localized cold downwellings (bright regions).

upwelling regions is typical of numerical results for internal heating (Figure $5 b$ ). This contrasts with Rayleigh-Bernard convection, where upwelling and downwelling fluid occur symmetrically. The instability in the bottom part of the plate that was discussed above might be expected to take the form of localized downwellings falling from the base of the plate.

\section{b. Observed Small-Scale Instability} in a Large-Scale Flow

Recently, Curlet [1976] conducted an experiment that has certain features in common with the suggested scheme for an instability at the base of the plate. Convection in glycerine was studied in a plexiglass enclosure, with a horizontal cross section of 24 inches $\times 20$ inches and a depth of 5 inches, in order to understand possible convective processes that might occur in glass furnaces. Neutrally buoyant anthracene particles were mixed in with the glycerine. The flow in longitudinal and transverse vertical sections through the tank could be visualized by illuminating the particles with a planar light source and taking streak (long exposure) photographs. A large-scale flow along one length of the tank was forced, as shown schemat- ically in Figure 9, by a combination of a uniform heat source over the top surface at one end of the tank and an isothermal heat sink over the other end of the tank. The source and sink extend the whole width of the tank. The production of a largescale flow in this way is to be expected, but what was unexpected was the behavior in planes transverse to the main flow (Figure 10). As the large-scale flow entered the region under the isothermal heat sink, cooling produced an upper boundary layer which eventually became unstable, producing convective rolls aligned along the direction of the large-scale flow.

Curlet [1976] calculated a local Rayleigh number for this upper boundary layer and showed that the onset of convective rolls occurred when $R a_{c} \sim 2 \times 10^{3}$, in agreement with the experiment in subsection $a$. For the purposes of comparison with possible mantle convection, various features of this experiment should be noted. First, the horizontal scale of the smallscale convection cells is much less than the depth of the tank. For the particular combination of boundary conditions in this experiment, where a small percentage of the heat loss occurs at the side boundaries, one observes a mean temperature structure under the sink which is potentially unstable in the upper 
boundary layer but stabilizing over a large part of the region below that. Such a temperature structure tends to prevent the penetration of the downwelling fluid into the fluid below [Whitehead and Chen, 1970]. Second, the longitudinal alignment of the small-scale convection cells is a result of the interaction with the large-scale flow [Richter and Parsons, 1975], a shear flow tending to suppress transverse rolls.

\section{Discussion and Conclusions}

A local Rayleigh number criterion used to test the stability of a boundary layer has been applied to the evolving thermal structure of the plates. It was demonstrated that it is likely that an instability in the bottom viscous region of the plate could lead to the development of small-scale convection. The same local Rayleigh number criterion applied to boundary layers has been shown to provide satisfactory results in a number of examples. The studies of Foster [1965a], Howard [1966], and Whitehead and Chen [1970] give some indication of why this is so. A cooling boundary layer above a semi-infinite region is always unstable. For a region of finite depth there will be some small critical Rayleigh number for the region as a whole to become unstable. However, the stability test is applied to a basic state that is time dependent. Any disturbances must grow fast enough not to be swamped by changes in this basic state. The disturbance for the layer as a whole will have the largest wavelength and low growth rates. As the cooling proceeds, the boundary layer itself becomes unstable, and this disturbance has a fast enough growth rate to dominate the time dependence of the basic state. Hence the stability of the whole region appears to be governed by the stability of the boundary layer.

In principle, the stability of any two-dimensional flow put forward as the large-scale circulation associated with plate motions could be tested exactly along the lines used by Busse [1967] for the stability of convective rolls. In practice, however, this is a difficult procedure. In any case, little is known about the circulation as a whole, solutions of the equations governing the behavior, or the rheology of the material involved. The part that seems to be best understood is the thermal structure of the plates, the boundary layer of the largescale flow. The above criterion provides a simple, albeit crude, method of testing for stability. Forsyth [1977] and Schubert et al. [1976] have suggested alternative explanations for the flattening in the depth versus age curve as discussed in the introduction, the mode of vertical heat transport being conductive in both cases. However, in neither case was the stability considered. The thermal structures of these models, as for the slab model, are closely similar. This must always be so in the age range where the $t^{i / 2}$ dependence of ocean depths holds. Hence the above arguments about stability apply equally to their models, and it appears possible that in both cases an instability will occur leading to the development of small-scale convection. We conclude therefore that the mode of vertical heat transport beneath the plates cannot be solely conductive. Though the boundary layer theory used above is crude, the results suggest that it should not be difficult with a more exact theory to obtain a consistent convective system. We have considered only one boundary layer instability. Other instabilities in the total circulation related to plate motions may be possible. These can only augment the arguments for convection on a different horizontal length scale beneath the plates. The occurrence of a convective instability and development of small-scale convection provide a consistent way of modeling the observed behavior, which is also consistent with the results of laboratory and numerical convection experiments. As the development of small-scale convection can account for the observations by itself, it is not necessary to suppose that additional effects such as shear stress heating contribute significantly to the thermal structure.

The depth to which cooling can penetrate into the mantle is essentially the sum of the thicknesses of the mechanical and thermal boundary layers. Figure 7 shows the relation of these to the plate thickness obtained by fits to depth versus age and heat flow versus age observations. Inversion of observed surface-wave velocities gives the depth to the low-velocity zone [Forsyth. 1977], and this is assumed to denote the onset of partial melting. In the past this depth was sometimes identified with the thickness of the plate used in thermal models. Figure 11 shows two estimates of the solidus of peridotite in the presence of water and the depth and temperature obtained for the bottom of the plate model that fits the depth and heat flow versus age data. It is clear that the onset of partial melting will occur at shallower depths than the plate thickness, so that estimates obtained from surface waves should differ from that obtained from thermal models. Figures 7 and 11 show that partial melting can occur within the thermal boundary layer, and a question that must be answered is whether the partial melting effects the rheological behavior and hence the thermal structure.

Such experiments as are available [Auten et al., 1974; Auten and Gordon, 1975; Arzi, 1974] suggest that the presence of small amounts of melt do not significantly affect the viscosity. In order to reduce the viscosity drastically it is not just sufficient that the melt wet the grain boundaries, forming a connected network of melt. In fact, in the derivation of the effective viscosity produced by diffusion creep [Herring, 1950; McKenzie, 1968] the shear stress on the grain boundaries is assumed to vanish. The amount of melting must be enough that the probability of solid-solid grain bonding is reduced,

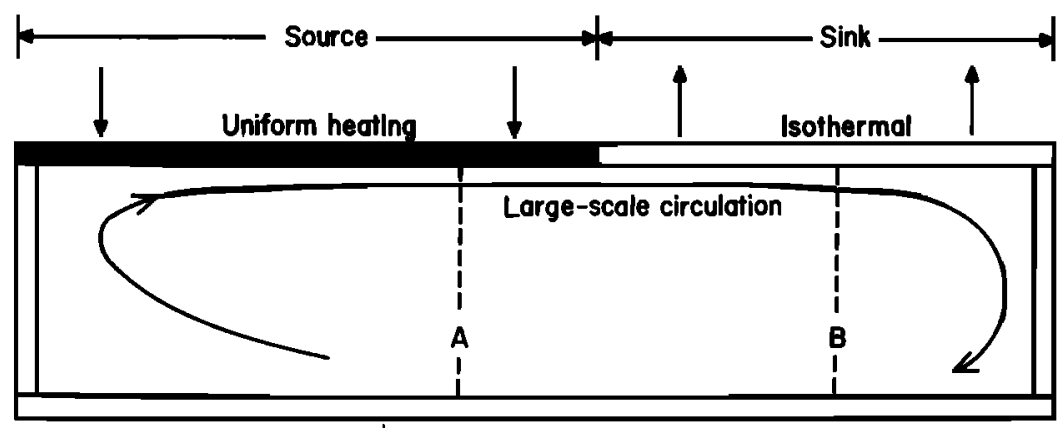

Fig. 9. Sketch of a longitudinal section of the experiment performed by Curlet [1976]. The dashed lines marked A and B denote transverse sections for which the flow is illustrated in the photographs of Figures $10 a$ and $10 b$, respectively. 


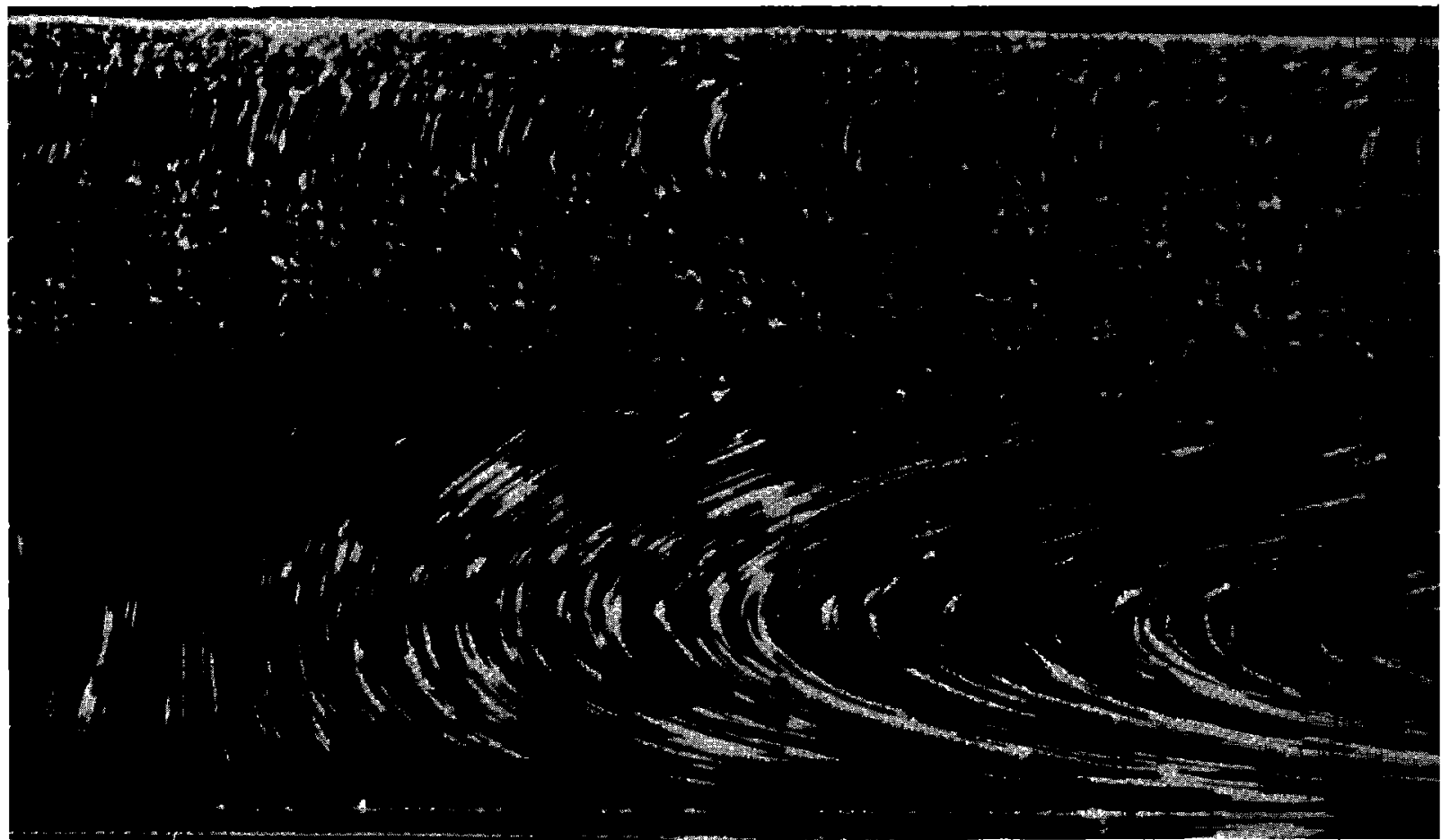

A

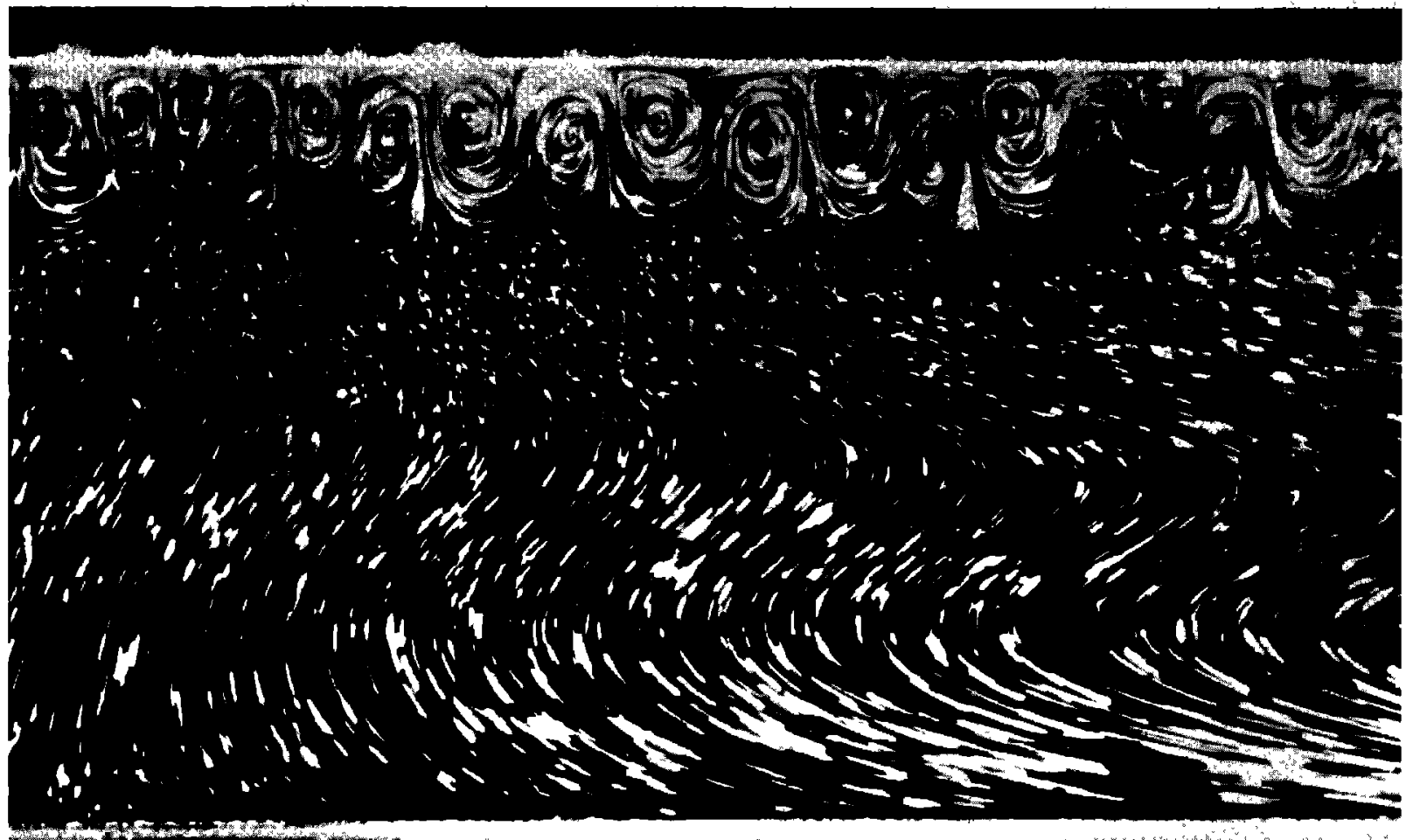

Fig. 10. (a) Photograph showing the flow in a transverse sectıon under the source region. The smooth curved streaks on the bottom of the photograph represent flow driven by heat losses at the side boundaries which is weak in comparison to the principal longitudinal large-scale flow. (b) Photograph illustrating the development of small-scale rolls under the cooling region. These occur when a local Rayleigh number, calculated for the upper boundary layer that forms in the sink region, exceeds a critical value [from Curlet, 1976]. 


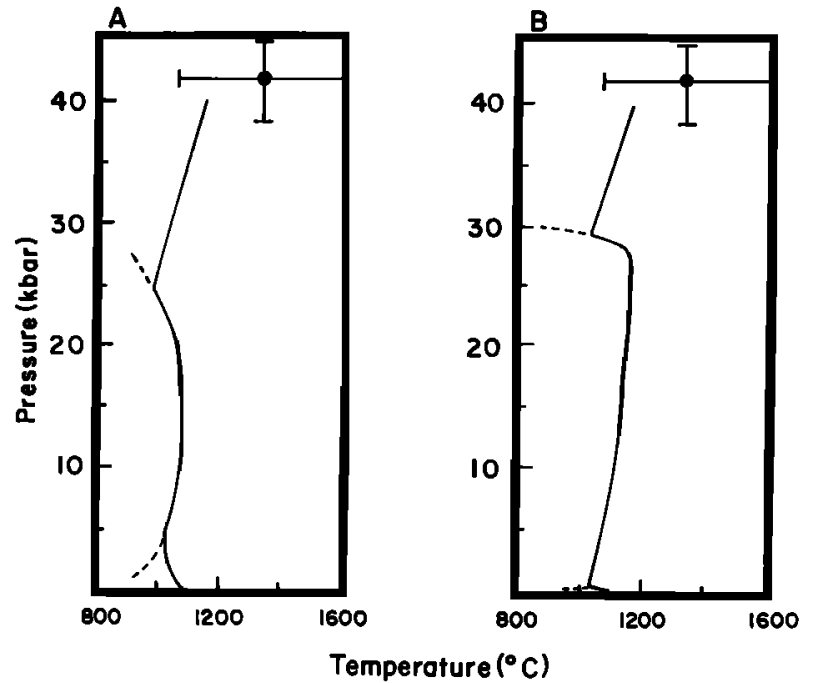

Fig. 11. The temperatures and depth, with estimated errors, determined for the base of the plate [from Parsons and Sclater, 1977], compared to two proposed melting curves for peridotite in the presence of small amounts of water. Curve A is from Millhollen et al. [1974], and curve B is from Green [1973].

and any interlocking of grains is small; otherwise, the viscosity is still primarily determined by transport within the solid grains. Although it is difficult to be specific with such meager experimental evidence, it is likely that the viscosity is not significantly reduced until the fraction of melt exceeds a critical amount ( 20\%; Arzi [1974]). The small amounts of melt that can be expected in the low-velocity zone, considering the relation of the temperatures to the wet and dry melting curves [Wyllie, 1971], should not substantially affect the viscosity. Any flow in this region will be undisturbed by the presence of partial melt. This is consistent with the observation of Forsyth [1977] that changes in seismic velocity structure clearly showed the effects of cooling within the low-velocity zone.

In a similar way the effective elastic plate thickness obtained from models representing the flexural effects of excess crustal loading [Watts and Cochran, 1974; McKenzie and Bowin, 1976] is obviously distinct from either the depth to the low-velocity zone or the thermally defined plate thickness. The measures provided by these different observational techniques are all related, however, by the thermal structure and the mechanical properties and melting behavior of mantle material. That the thermal models, depth to the low-velocity zone, and depth of the lithosphere/asthenosphere transition should all give different estimates of plate thickness is not because there is any conflict between the models used but because in each case one is looking at different physical properties for which the dependence on the thermal structure varies.

In order to distinguish between the different thermal models of the plates the most obvious discriminating feature is the presence or absence of small-scale convection. Attempts to provide direct evidence for mantle convection have been made recently by studying relations between long-wavelength gravity and elevation anomalies [Menard, 1973; Sclater et al., 1975; Watts, 1976]. Although the anomalies observed and the relations between them can be convincingly explained as the results of convection, the wavelengths involved were not clearly determined. McKenzie and Bowin [1976] attempted to detect small-scale convection by studying the relation between gravity and bathymetry as a function of wavelength along single profiles in the North Atlantic. Their results could be explained in terms of variations in crustal thickness and an associated mechanism for isostatic compensation. The exact wavelength of the small-scale convection seriously affects attempts to detect it. The theoretical studies of Foster [1965a] and Whitehead and Chen [1970] suggest that the wavelength could be independent of the depth, being determined solely by the amount of heating. The wavelength would also be affected by the viscosity structure in the upper mantle, any increase in viscosity with depth tending to reduce the penetration and hence the wavelength of the convection. If the wavelength is too small $(<400 \mathrm{~km})$, the masking effect of the overlying elastic plate will make it difficult to detect by trying to observe associated depth and gravity anomalies [McKenzie and Weiss, 1975]. Without a direct demonstration of small-scale convection, discriminating between thermal models of the plates will depend solely on theoretical arguments such as those given above. It is possible but unlikely that a full nonlinear study of the thermal boundary layer instability combined with the depth-age curves will provide information about any convective motions involved.

Acknowledgments. This research was started while both authors were participants in the Geophysical Fluid Dynamics Program at Woods Hole Oceanographic Institution in 1975. We would like to thank Willem Malkus for encouragement then and since. Nigel Curlet kindly gave us permission to reproduce the photographs in Figure 9 We are grateful to Jack Whitehead for experimental facilities and to Bob Frazel for assistance in building apparatus and with photography. The work was principally supported by the Office of Naval Research under grant N0014-75-C-0291. Research on mantle convection at Cambridge, England, is supported by a grant from the Natural Environmental Research Council.

\section{REFERENCES}

Arzi, A. A., Partial melting in rocks: Rheology, kinetics and water diffusion, Ph.D. thesis, Harvard Univ., Cambridge, 1974.

Auten, T. A., and R. B. Gordon, Compressive creep rates of partially melted Al-Ga alloys, Met. Trans., 6a, 584-586, 1975.

Auten, T. A., R. B. Gordon, and R. L. Stocker, $Q$ and mantle creep, Nature, 250, 317-318, 1974.

Busse, F. H., On the stability of two-dimensional convection in a layer heated from below, J. Math. Phys., 46, 140-150, 1967.

Cathles, L. M., The viscosity of the earth's mantle, Ph.D. thesis, Princeton Univ., Princeton, N. J., 1971.

Chen, M. M., and J. A. Whitehead, Evolution of two-dimensional periodic Rayleigh convection cells of arbitrary wavenumbers, $J$. Fluid Mech., 3I, 1-15, 1968.

Crough, S. T., Thermal model of oceanic lithosphere, Nature, 256. 388-390, 1975.

Curlet, N. W. E., Experimental and numerical modeling of three dimensional natural convection in an enclosure, $\mathrm{Ph} . \mathrm{D}$. thesis, Mass. Inst. of Technol., Cambridge, 1976.

Davis, E. E., and C. R. B. Lister, Fundamentals of ridge crest topography, Earth Planet. Sci. Lett., 21, 405-413, 1974.

Forsyth, D. W., The early structural evolution and anisotropy of the oceanic upper mantle, Geophys. J. Roy. Astron. Soc., 43, 103-162, 1975.

Forsyth, D. W., The evolution of the upper mantle beneath mid-ocean ridges, Tectonophysics, 38, 89-118, 1977.

Foster, T. D., Stability of a homogeneous fluid cooled uniformly from above, Phys. Fluids, 8, 1249-1257, 1965a.

Foster, T. D., Onset of convection in a layer of fluid cooled from above, Phys. Fluids, 8, 1770-1774, 1965 b.

Frey, F. A., W. B. Bryan, and G. Thompson, Atlantic Ocean floor: Geochemistry and petrology of basalts from legs 2 and 3 of the Deep Sea Drilling Project, J. Geophys. Res., 79, 5507-5527, 1974.

Green, D. H., Magmatic activity as the major process in the chemical evolution of the earth's crust and mantle, Tectonophysics, 13, 47-71, 1972.

Green, D. H., Experimental melting studies on a model upper mantle composition at high pressures under water-saturated and waterundersaturated conditions, Earth Planet. Sci. Lett., 19, 37-53, 1973.

Green, D. H., and R. C. Liebermann, Phase equilibria and elastic properties of a pyrolite model for the oceanic upper mantle, Tectonophysics, 32, 61-92, 1976. 
Herring, C., Diffusional viscosity of a polycrystalline solid, J. Appl. Phys., 21. 437-445, 1950.

Howard, L. N., Convection at high Rayleigh number, in Proceedings of 11 th International Congress of Applied Mechanics, Munich, 1964. edited by H. Görtler, pp. 1109-1115, Springer, New York, 1966.

Kausel, E. G., A. R. Leeds, and L. Knopoff, Variations of Rayleigh wave phase velocities across the Pacific Ocean, Science, 186, 139$141,1974$.

Kohlstedt, D. L., and C. Goetze, Low-stress high-temperature creep in olivine single crystals, J. Geophys. Res., 79, 2045-2051, 1974.

Leeds, A. R., Lithospheric thickness in the western Pacific, Phys. Earth Planet. Interiors, 11, 61-64, 1975.

Leeds, A. R., L. Knopoff, and E. G. Kausel, Variations of upper mantle structure under the Pacific Ocean, Science, 186, 141-143, 1974.

Lister, C. R. B., Estimators for heat flow and deep rock properties based on boundary layer theory, Tectonophysics, 41, 157-171, 1977.

McKenzie, D. P., Some remarks on heat flow and gravity anomalies, J. Geophys. Res., 72, 6261-6273, 1967.

McKenzie, D. P., The geophysical importance of high-temperature creep, in The History of the Earth's Crust, edited by R. A. Phinney, Princeton University Press, Princeton, N.J., 1968.

McKenzie, D., and C. Bowin, The relationship between bathymetry and gravity in the Atlantic Ocean, J. Geophys. Res., 81, 1903-1915. 1976.

McKenzie, D., and N. Weiss, Speculations on the thermal and tectonic history of the earth, Geophys. J. Roy. Astron. Soc., 42, 131174, 1975.

McKenzie, D. P., J. M. Roberts, and N. O. Weiss, Convection in the earth's mantle: Towards a numerical simulation, J. Fluid Mech., 62, 465-538, 1974.

Menard, H. W., Depth anomalies and the bobbing motion of drifting islands, J. Geophys. Res., 78, 5128-5137, 1973.

Millhollen, G. L., A. J. Irving, and P. J. Wyllie, Melting interval of peridotite with 5.7 per cent water to 30 kilobars, J. Geol., 82, 575$587,1974$.

Oldenburg, D. W., A physical model for the creation of the lithosphere, Geophys. J. Roy. Astron. Soc., 43, 425-451, 1975.

Parker, R. L., and D. W. Oldenburg, Thermal model of ocean ridges, Nature Phys. Sci., 242, 137-139, 1973.

Parsons, B., and J. G. Sclater, An analysis of the variation of ocean floor bathymetry and heat flow with age, J. Geophys. Res., 82, 803$827,1977$.

Peltier, W. R., and J. T. Andrews, Glacial-isostatic adjustment, I, The forward problem, Geophys. J. Roy. Astron. Soc., 46. 605-646, 1976.

Post, R. L., High temperature creep of Mt. Burnett dunite, Tectonophysics, 42, 75-110, 1977.
Richter, F. M., Convection and the large-scale circulation of the mantle, J. Geophys. Res., 78, 8735-8745, 1973.

Richter, F. M., On the driving mechanism of plate tectonics, Tectonophysics, 38, 61-88, 1977.

Richter, F. M., and D. McKenzie, Simple plate models of mantle convection, J. Geophys., in press, 1978.

Richter, F. M., and B. Parsons, On the interaction of the two scales of convection in the mantle, J. Geophys. Res., 80, 2529-2541, 1975.

Scheidegger, K. F., Temperatures and compositions of magmas ascending along mid-ocean ridges, J. Geophys. Res., 78, 3340-3355, 1973.

Schubert, G., C. Froidevaux, and D. A. Yuen, Oceanic lithosphere and asthenosphere: Thermal and mechanical structure, J. Geophys. Res., 81. 3525-3540, 1976.

Sclater, J. G., L. A. Lawver, and B. Parsons, Comparison of longwavelength residual elevation and free air gravity anomalies in the North Atlantic and possible implications for the thickness of the lithospheric plate, J. Geophys. Res., 80, 1031-1052, 1975

Spangenberg, W. G., and W. R. Rowland, Convective circulation in water induced by evaporative cooling, Phys. Fluids, 4, 743-750, 1961

Stocker, R. L., and M. F. Ashby, On the rheology of the upper mantle, Rev. Geophys. Space Phys., II, 391-426, 1973.

Turcotte, D. L., and E. R. Oxburgh, Finite amplitude convective cells and continental drift, J. Fluid Mech., 28, 29-42, 1967.

Watts, A. B., Gravity and bathymetry in the central Pacific Ocean, $J$. Geophys. Res., 8I, 1533-1553, 1976.

Watts, A. B., and J. R. Cochran, Gravity anomalies and flexure of the lithosphere along the Hawaiian-Emperor seamount chain, Geophys. J. Roy. Astron. Soc., 38, 119-141, 1974.

Weidner, D. J., Rayleigh wave phase velocities in the Atlantic Ocean, Geophys. J. Roy. Astron. Soc., 36, 105-139, 1974.

Whitehead, J. A., and M. M. Chen, Thermal instability and convection of a thin fluid layer bounded by a stably stratified region, $J$. Fluid Mech., 40, 549-576, 1970.

Whitehead, J. A., and B. Parsons, Observations of convection at Rayleigh numbers up to 760,000 in a fluid with large Prandtl number, Geophys. Astrophys. Fluid Dyn., 9, 201-217, 1978.

Wyllie, P. J., The Dynamic Earth: Textbook in Geosciences, pp. 196208, John Wiley, New York, 1971.

(Received July 5, 1977; revised March 6, 1978; accepted May 4, 1978.) 